\title{
Composite and Preferences Scales of Morningness: Reliability and Factor Invariance in Adult and University Samples
}

\author{
Juan Francisco Díaz Morales \\ María Pilar Sánchez-López \\ Complutense University of Madrid
}

\begin{abstract}
The creation and adaptation of scales or inventories assessing specific circadian typologies has been a predominant focus within the field of chronopsychology. The present study addressed the psychometric properties of two scales of morningness-eveningness: the Morningness Composite Scale (CS; Smith, Reilly, \& Midkiff, 1989) and the Early/Late Preferences Scale (PS; Smith, Folkard, Schmieder, Parra, Spelten, \& Almirall, 1993). Internal consistency and factor invariance of the CS and PS were analyzed in two samples: a group of 203 university students (age range $=19-30$ ) and a group of 125 working adults (age range $=31-65$ ). Results indicated satisfactory internal consistency for both full scales with each age group and confirmed the factor invariance across age for the two CS factors and one of the PS factors. A higher tendency in morningness on both scales was noted in the adult sample.
\end{abstract}

Keywords: morningness-eveningness, undergraduates, adults, reliability, factor invariance, age differences

\begin{abstract}
Uno de los campos de estudio más desarrollado por la cronopsicología ha sido la creación y adaptación de escalas o inventarios para evaluar la tipología circadiana. En este estudio se presentan las propiedades psicométricas de dos escalas de evaluación de la matutinidad-vespertinidad: Ia Escala Compuesta de Matutinidad (CS; Smith, Reilly y Midkiff, 1989) y la Escala de Preferencias (PS; Smith, Folkard, Schmieder, Parra, Spelten y Almirall, 1993). Para cada escala, se analizó tanto la consistencia interna como la invarianza factorial en dos muestras: un grupo de 203 universitarios (edad entre 19 y 30 años) y un grupo de trabajadores adultos (edad entre 31-65 años). Los resultados indican una consistencia interna adecuada para cada una de las escalas en ambos grupos, así como una estructura factorial invariante en función de la edad para los dos factores de la CS y uno de los factores de la PS. Aparece una mayor tendencia a la matutinidad en el grupo adulto.

Palabras clave: matutinidad-vespertinidad, universitarios, adultos, fiabilidad, invarianza factorial, diferencias de edad
\end{abstract}

Correspondence concerning this article should be addressed to Juan Francisco Díaz Morales, Departamento de Psicología Diferencial y Psicología del Trabajo, Facultad de Psicología. Universidad Complutense de Madrid. Campus de Somosaguas. 28223 Madrid (Spain). E-mail: juanfcodiaz@psi.ucm.es 
Research in both chronobiology and chronopsychology provides important findings on the differential nature of the circadian rhythm, most particularly between morning and evening chronotypes (Carrier \& Monk, 2000; Folkard \& Monk, 1985; Kerkhof, 1985; Webb, 1982). Preference for timeframe-related activities is considered a reliable behavioral measurement of the tendency for morningness and eveningness. The underlying mechanism of this typology is the variability of a set of psychological, behavioral, and biological variables which have roughly a 24-hour oscillation (i.e., a circadian rhythm). This orderly series of changes has been demonstrated from the analysis of both biological (e.g., body temperature and levels of hormone secretion) and psychological variables (e.g., mood and performance).

The practical implications of these findings have been applied to diverse fields such as the design of working hours (Furham \& Hughes, 1999; Härmä, 1993), athletic performance (Smith, Guilleminault, \& Efron, 1997), academic performance (Testu, 1989), and, in general, health and psychological wellbeing (Bohle, 1989; Mecacci \& Rochetti, 1998). The creation and adaptation of scales or inventories enabling the circadian typology (or morningness) to be specified has taken up a large number of the works in this area (Adan \& Almirall, 1991; Brown, 1993; Folkard, Monk, \& Lobban, 1979; Horne \& Östberg, 1976; Moog, 1981; Roberts \& Irvine, 1999; Smith et al., 1993; Torsvall \& Akerstdt, 1980).

With the aim of achieving a reliable and valid measurement of morningness, Smith, Reilly, and Midkiff (1989) created the Composite Scale of Morningness (CS) by using the best questions from the MorningnessEveningness Questionnaire (MEQ, Horne \& Östberg, 1976) and the Diurnal Type Scale (DTS, Torsvall \& Åkerstdt, 1980). In particular, the psychometric properties of the CS have been described by Smith et al. (1989) and, since then, subsequent studies have corroborated its reliability and validity (Bohle, Tilley, \& Brown, 2001; Brown, 1993; Caci, Nadalet, Staccini, Myquel, \& Boyer, 1999; Greenwood, 1994; Guthrie, Ash, \& Bendapudi, 1995; Natale \& Alzani, 2001; Pornpitakpan, 1998; Smith et al., 2002; Zickar, Russell, Smith, Bohle, \& Tilley, 2002). The CS has been translated into French (Caci et al., 1999), Thai (Pornpitakpan, 1998), and Italian (Natale \& Alzani, 2001).

Subsequently, Smith et al. (1993) created the Early/Late Preferences Scale (PS), comprised of 12 items. The creation of the PS was an attempt to solve some of the psychometric problems of the CS, such as the use of different response scales in some of the items and the methodological problem of including items referring to specific hours of the day. Having solved these problems, the PS is more suitable for evaluating the morningness of people with atypical or irregular sleep habits, and is the least complex format with a consistent response scale. The psychometric properties of the PS have been analyzed in different countries along with the CS. In Bohle's (2001) study, an alpha coefficient of .86 was obtained, whereas in the work of Smith et al. (2002), the alpha coefficient ranged from .81 to .90 . The correlations with the perceived activation level and the preference for going to bed and getting up were those that were theoretically expected.

The relationship between the CS and the PS was high ( $r$ $=.76$ ), which indicates adequate convergent validity. The PS yielded two invariant factors in six countries. The first factor (Items 3, 4, 6, 10, and 12) can be defined as a "general activities factor," whereas Factor II (Items 1, 2, 5, and 8) "deals specifically with getting up and going to bed" (Smith et al., 2002, p. 960). Not all the studies using the CS provide data about the factor structure. Smith et al. (1989), found three factors (Effort, Eveningness, and Alertness) after jointly analyzing the factor structure of the MEQ and CTQ. Other studies, which specifically analyze the internal structure of the CS or the Basic Language Morningness Scale (BALM) coincide in showing two or three factors (Brown, 1993; Pornpitakpan, 1998, 2000). Moreover, when a comparison is made of the elements making up the factors obtained in the studies in which the factor structure of the CS is analyzed, there is a some accordance among the findings. Thus, for example, Smith et al.'s (1989) Factor I is made up of elements 4, 5, 9, 11, and 16 from the MEQ, and Smith, Tisak, Bauman, and Green's (1991) Alertness factor is made up of elements 4, 5, and 7 from the MEQ (Items 3, 4, and 5 from the CS). Natale and Cicogna's (1996) Wake-up factor is made up of elements 1, 4, 5, 7, and 9 from the MEQ. Brown (1993), using two samples of workers on the day- and rotating-shifts, obtained three factors. Brown's Alertness factor is made up of Items 3, 4, 5, and 12 from the BALM. Pornpitakpan (1998) discovered three factors in university students. This author simplified the scale by creating a reduced version with a bi-factor structure; nevertheless, Factor II of her initial analysis was made up of Items 4, 5, and 12 from the BALM. Also with university students, two factors were obtained by Roberts and Kyllonen (1999), who only used a general morningness factor. Bohle et al. (2001) opted for the one-dimensional nature of the scale despite two factors being viable. Finally, Smith et al. (2002, p. 963) demonstrated the factor invariance of a model for measuring the two correlated factors of the CS in six countries: a first factor made up of Items 3, 4, 5 and 12, and which they called a General Morning factor and a second factor made up of Items $1,2,6,7,8,9,10$, and 11 , which "cannot be easily labeled". In summary, despite the fact that in nearly all studies, two or three factors are viable, most authors opt for the onedimensional nature of the CS and PS (Smith et al., 1991; Bohle et al, 2001). Smith et al. (2002) reported evidence of group-level consistency in factor form and loadings for the Alertness factor in Japanese and American populations.

Subsequently, Smith et al. (2002), using simultaneous factor analysis in several populations (USA, England, The Netherlands, Colombia, Spain, and India) showed grouplevel consistency in the psychometric properties of the morningness construct (factor form and loadings). Mean 
level differences were observed between the respondents in warm climates (Colombia, Spain, and India), where people perceive themselves to be more morning-oriented, and the people who live in cooler climates (USA, England, and The Netherlands). The results reported by Smith et al. (1991, 2002) provide support for the assumption that true grouplevel differences may exist in the morningness construct, as the factor form and loadings are invariant across samples.

Most studies indicate that with age there is a gradual change towards morningness. This result seems fairly consistent and has been confirmed in samples of very diverse characteristics (Tankova, Adan, \& Buela-Casal, 1994). According to Koscec, Radosevic-Vidacek, and Kostovic (2001, p. 628), "It has been demonstrated that engagement in an occupation, which results in a more constraining way of life, shifts scores on the morningness-eveningness questionnaires towards morningness." In this sense, our aim is to analyze age differences in morningness by previously determining whether the morningness construct (factor form and loadings) is equivalent in a university and adult sample. In accordance with the previously presented findings, a model for measurement in two correlated factors for the CS and PS seems reasonable. In the case of the CS, the Alertness factor appears consistently in different samples and with different methods of exploratory factor analysis. Items 4 and 5 refer to how clear-headed or tired the subject feels during the first half hour after waking up, whereas Item 12 evaluates the time required to become clear-headed after a night's sleep. The measurement model with two correlated factors (Factor $I=1,2,3,6,7,8,9,10$, and 11, and Factor II $=4,5$, and 12) shows satisfactory adjustment in undergraduates (Díaz Morales \& Sánchez-López, in press). In the case of the PS, an exploratory factor structure was obtained in two factors (Factor I = Items 1, 2, 5, 8, and 9, and Factor II = Items 3, 4, 6, 10, and 12) very similar to the ones obtained by Smith et al. (2002).

Thus, the aims of this study are to provide detailed information about the psychometric properties of the CS and PS: (a) to describe internal consistency for the full scales, (b) to analyze the factor structure of both scales, and, (3) to assess the invariance of morningness across two age cohorts, namely university and adult groups. The findings of this study can be compared with those obtained by Bohle et al. (2001) and Smith et al. (2002).

\section{Method}

\section{Participants}

The sample consisted of 329 participants of whom (247) $76.2 \%$ were women. The age range was from 19 to 62 years $(M=31.78, S D=14.18)$. Young undergraduates comprised (203) $61.7 \%$ of the sample, whereas the remaining (126) $38.3 \%$ was made up of a group of adults.
The average age for the undergraduate group was 21.27 years $(S D=1.6)$, with ages ranging between 19 and 30 years. Women made up $81 \%$ of the sample. The average age for the adult group was 49.1 years $(S D=6.31)$, with ages between 32 and 62 . Women comprised $66.7 \%$ of the sample. Participants were recruited using a "snowball" technique, in which a group of psychology undergraduates from the Complutense University of Madrid administered the test to two people from their circle of friends, with some restrictions in order to maintain a balance of sex and age distribution.

\section{Instruments}

Composite Scale of Morningness (CS; Smith et al., 1989). The CS is made up of 13 items with a Likert-type response format. Five of the scale elements refer to different times of the day. The score obtained from the sum of the items ranges from 13 to 55 . The CS has been translated into Spanish by Díaz Ramiro (2000). The definitive version was used in a sample of undergraduates and adults and showed excellent psychometric properties, as well as adequate predictive validity in a group of workers with rotating shifts. The scale's convergent validity is adequate with regard to the MEQ $(r=0.79)$.

Early/Late Preference Scales (PS; Smith et al., 1993). The PS is made up of 12 items which do not refer to specific times of day, but rather to the subject's preference for carrying out different activities compared to the reference group. The score obtained on the scale is calculated by the sum of all the items, with a range from 12 to 60 . The PS has been translated into Spanish by the authors of this work. A pilot study was made with a group of university students who analyzed the aspects of writing and understanding the items.

\section{Procedure}

Both samples of participants completed the CS and PS, along with other personality tests, in 1-hour morning and afternoon sessions during the months of March and April. No participant in this study was paid. To analyze the psychometric properties of each of the scales, descriptive statistics were calculated, including item-scale correlation, reliability (Cronbach's alpha), and confirmatory factor analysis (CFA) (Byrne, Shavelson, \& Muthén, 1989). Data analyses were carried out with the SPSS-X (1988) and LISREL 8.30 (Jöreskog \& Sörbom, 1993) statistical packages.

\section{Results}

\section{Descriptive Statistics and Reliability}

The CS values ranged between 13-51 (theoretical range is 13-55). For the sample as a whole the mean was 31.48 
$(S D=6.73)$. The distribution of the scale was normal (Kolmogorov-Smirnov $Z=1.21, p=.13$ ). The university group was more evening oriented than the adult group ( $(M$ $=28.9, S D=6.14$ and $M=35.57, S D=5.55$, respectively), $t(325)=9.81, p<.001$. The values corresponding to the $10^{\text {th }}$ and $90^{\text {th }}$ percentiles were $21 / 37$ and $28 / 42$ for the university and adult samples, respectively. The undergraduates taking part in this study showed a greater tendency to eveningness $(M=28.9, S D=6.14)$ compared with the Spanish subsample used by Smith et al. (2002) for the CS $(M=33.9, S D=5.8)$.

Again, for the sample as a whole, the mean of the PS was $33.5(S D=6.57)$. The distribution of frequencies did not differ from the normal curve (Kolmogorov-Smirnov $Z=0.33, p=$ .33). The group of undergraduates was once again more evening oriented than the adult group $(M=31.96, S D=6.22$ and $M=36.02, S D=6.35$, respectively), $t(324)=5.67, p<$ .0001 . The values corresponding to the $10^{\text {th }}$ and $90^{\text {th }}$ percentiles were $24 / 40$ and $28 / 44$ for youths and adults, respectively. Compared to the Spanish university subsample $(M=36.4, S D$ = 6.0) of Smith et al. (2002) and to the Australian undergraduates $(M=35.1, S D=7.1)$ of Bohle et al. (2001), the sample of undergraduates participating in this work showed a greater tendency towards eveningness $(M=33.5, S D=6.57)$. The relationship between the CS and PS for the undergraduate group, $r=.78, p<.001$, was slightly higher than for the adult group, $r=.71, p<.001$. This correlation indicates that there is considerable overlap between the two scales and that both scales measure the same construct. In the studies of Bohle et al. (2001) and Zickar et al. (2002) similar values were obtained $(r=.83$ and $r=.76$, respectively). Both scales are related to age when the whole sample is jointly considered (age range = 19-62). The correlation of age with the CS, $r=.49, p<$ .001 , was higher than with the PS, $r=.31, p<.001$. There were no sex-related differences in any of the groups considered. These findings corroborate those found by Bohle et al. (2001) and Zickar et al. (2002).

Tables 1 and 2 show Cronbach's alpha coefficient, the corrected item-total correlation, and $\alpha$ if-item-deleted from the full scale for the undergraduate and adult groups of both scales, the CS and the PS.

The internal consistency of the complete CS is acceptable for both groups. The alpha coefficient for the university students was .85 (item-total correlation range was .41-.65). In the Spanish subsample used by Smith et al. (2002), the alpha coefficient was .81 (item-total correlation range was .27-.66). The alpha coefficient for adults showed a noticeable drop to .79 (item-total correlation range was .24-.61), with Item 6 ("doing exercise from 7:00 to 8:00 in the morning") being the only one that showed a low correlation (.24) with the scale. Cronbach's alpha values were within the indices found in other studies (Bohle et al., 2001; Smith et al., 2002).

The internal consistency of the complete PS was acceptable for both groups. In the undergraduate group, the alpha coefficient was .83 (item-total correlation range was .19-.64), with Items 7 and 11 showing the lowest correlation coefficients (.27 and .18, respectively). In the group of adults, the alpha coefficient was .85 (item-total correlation range was .26-.70) and only Item 7 showed a low correlation coefficient (.26). Bohle et al. (2001) obtained an alpha of .86 , and this is within the range of values (.80-.90) found by Smith et al. (2002).

Table 1

The Composite Scale of Morningness (CS, Smith et al., 1993) Item-Total Correlations with Reliability Estimates in Two Samples

\begin{tabular}{|c|c|c|c|c|}
\hline \multirow{3}{*}{ CS Items } & \multicolumn{4}{|c|}{ Samples } \\
\hline & \multicolumn{2}{|c|}{ Students $19-29$ years $(n=201)$} & \multicolumn{2}{|c|}{ Adults $30-62$ years $(n=123)$} \\
\hline & Corrected item-total correlation & $\alpha$ if item deleted & Corrected item-total correlation & $a$ if item deleted \\
\hline 1 & .50 & .84 & .45 & .78 \\
\hline 2 & .46 & .84 & .45 & .78 \\
\hline 3 & .52 & .84 & .41 & .78 \\
\hline 4 & .57 & .84 & .42 & .78 \\
\hline 5 & .52 & .84 & .36 & .79 \\
\hline 6 & .41 & .85 & .24 & .80 \\
\hline 7 & .46 & .84 & .41 & .78 \\
\hline 8 & .43 & .85 & .33 & .79 \\
\hline 9 & .60 & .84 & .49 & .78 \\
\hline 10 & .50 & .84 & 61 & .77 \\
\hline 11 & .59 & .84 & .49 & .78 \\
\hline 12 & .44 & .85 & .38 & .78 \\
\hline 13 & .65 & .83 & .55 & .77 \\
\hline
\end{tabular}

Standardized

item $a$ 
Table 2

The Preferences Scale of Morningness (PS, Smith et al., 1993) Item-Total Correlations with Reliability Estimates in Two Samples

\begin{tabular}{|c|c|c|c|c|}
\hline \multirow{3}{*}{ CS Items } & \multicolumn{4}{|c|}{ Samples } \\
\hline & \multicolumn{2}{|c|}{ Students $19-29$ years $(n=195)$} & \multicolumn{2}{|c|}{ Adults $30-62$ years $(n=121)$} \\
\hline & Corrected item-total correlation & $a$ if item deleted & Corrected item-total correlation & $a$ if item deleted \\
\hline 1 & .64 & .80 & .68 & .83 \\
\hline 2 & .37 & .82 & .40 & .85 \\
\hline 3 & .54 & .81 & .56 & .84 \\
\hline 4 & .63 & .80 & .61 & .84 \\
\hline 5 & .54 & .81 & .46 & .85 \\
\hline 6 & .53 & .83 & .53 & .84 \\
\hline 7 & .28 & .80 & .26 & .86 \\
\hline 8 & .63 & .82 & .64 & .83 \\
\hline 9 & .39 & .82 & .44 & .85 \\
\hline 10 & .63 & .80 & .70 & .83 \\
\hline 11 & .19 & .84 & .48 & .84 \\
\hline 12 & .52 & .81 & .57 & .84 \\
\hline
\end{tabular}

Standardized

item $a$

.85

\section{Factor analysis}

Although the CS and PS were used as one-dimensional instruments, most of the studies of their factor structures yielded two or three factors. As mentioned, there is some consistency across studies about the bi-factor structure of both scales. In line with one of these studies and the previous findings in the Spanish university population (Díaz Morales \& Sánchez-López, in press; Smith et al., 2002) on the factor structure of the CS and PS, the equivalence of a measurement model for two correlated factors in the university and adult groups was analyzed (Byrne et al., 1989; Jöreskog, 1971). Tests for the factor structure and invariance across age groups of the morningness measures were based on the analysis of covariance structures. Multiple group confirmatory factor analysis was used to test for factor invariance, using LISREL methodology (Jöreskog \& Sörbom, 1993) and maximum likelihood estimation procedures. Multiple indices were used to evaluate goodness of fit. Model fit was based on several recommended criteria (Bentler, 1992): the chi-square test $\left(\chi^{2}\right)$, the comparative fit index $(\mathrm{CFI}>.85)$, the non-normed fit index $(\mathrm{NNFI}>.90)$, the goodness-of-fit index (GFI > .90), and the root mean square error of approximation $($ RMSEA < .10).

Morningness Composite Scale. In the first stage, a twofactor baseline model was estimated separately for university students and older adults. This procedure allowed for confirmation of the underlying factor structure of morningness measures for each age group and fulfilled the requirements for testing for factor invariance (Luijben, 1989). Preliminary single-group analyses showed a "reasonable" baseline model for both university and adult groups. A two-factor congeneric measurement model was a marginal explanation for university students, $\chi^{2}(64, N=201)=185.55, p<.001($ RMSEA $=$ $.097, \mathrm{CFI}=.86, \mathrm{GFI}=.88, \mathrm{NNFI}=.83)$ and adult groups, $\chi^{2}(64, N=123)=126.74, p<.001(\mathrm{RMSEA}=.090, \mathrm{CFI}=$ .85 , GFI $=.86, \mathrm{NNFI}=.82$ ). To achieve a well-fitting model, the original model for each group was modified by relaxing significant error covariances, using the Language Multiplier chi square statistic. In post hoc model fitting, the goal is to achieve parsimony by freeing no more than about $5 \%$ of the error covariances. One error covariance (Items 2-7 for university students and Items 9-13 for adults) was relaxed in each age group. For the university students, the fit of the final model was acceptable, $\chi^{2}(63, N=201)=137.18, p<$ $.001(\mathrm{RMSEA}=.077, \mathrm{CFI}=.90, \mathrm{GFI}=.89, \mathrm{NNFI}=.91)$. For the older adults, the fit of the final model was also an improvement, $\chi^{2}(63, N=123)=103.88, p<.001($ RMSEA $=.073, \mathrm{CFI}=.88, \mathrm{GFI}=.88, \mathrm{NNFI}=.90)$.

The second model was estimated simultaneously for the university and adult group to provide a baseline model against which to compare more restrictive models. The first hypothesis tested was that the two-factor structure is invariant across age. The results of this analysis showed that a twofactor solution represents a reasonable fit to the data, $\left(\chi^{2}(130)=269.56 ; d f=130 ; p<.05 ;\right.$ RMSEA $=.082$, CFI $=.87, \mathrm{GFI}=.87, \mathrm{NNFI}=.89)$. In the subsequent model, all estimable factor loading parameters were constrained equal across groups as a test of measurement invariance. As the difference in $\chi^{2}$ was nonsignificant $\left(\Delta \chi^{2}(11)=12.64\right.$, $p>.05)$, the hypothesis of an invariant pattern of factor 
loadings was tenable. The result of the multigroup analysis to test whether the groups have different mean levels showed that the adult subgroup was lower than the university subgroup in each of the two morningness factors as measured by this scale $(M=0.61, S E=0.07, t$-value $=8.64$ in Factor I, and $M=0.58, S E=0.08, t$-value $=7.15$ in Factor II)

The robustness of Factor II (Items 4, 5 and 12) must be stressed. Factor II-Alertness — is similar to Smith's (1991) Factor III, which was made up of MEQ Items 4, 5 and 7 (Items 3, 4, and 5 from the CS). This factor is the only invariant in the samples of subjects used in this study: the American one by Smith et al. (1989) and the Japanese by Ishihara, Saitoh, Inoue, and Miyata (1984). It also coincides with Brown's (1993) Factor II, which is known as Morningness-Alertness, and with factor II (4, 5, and 12) of Pornpitakpan's (1998). Lastly, it is similar to Factor I of Smith et al. (2002), which the authors called General Morningness factor (this factor also includes Item 3).

Early/Late Preferences Scale. The same procedure was followed for the PS. The model for the university group, $\chi^{2}$ $(53, N=195)=63.92, p=.14$, RMSEA $=.041, \mathrm{CFI}=.97$, GFI $=.92$, NNFI $=.96$, showed a very acceptable adjustment. This was not the case of the adult group, $\chi^{2}$ $(53, \mathrm{~N}=121)=142.78, p<.001, \mathrm{RMSEA}=.092, \mathrm{CFI}=$ $.87, \mathrm{GFI}=.89, \mathrm{NNFI}=.84$. None of the modification indices produced a substantial improvement in the model.

Once the factor structure in both groups had been analyzed, the following model was estimated simultaneously for the university and adult groups to provide a baseline model against which to compare more restrictive models. The results of this analysis showed that a two-factor solution represented a reasonable fit to the data $\left(\chi^{2}=207.11, d f=\right.$ $107, p<.001, \mathrm{RMSEA}=.076, \mathrm{CFI}=.91, \mathrm{GFI}=.92, \mathrm{NNFI}$ $=.89)$. Then, all estimable loading parameters were constrained equal across groups as a test of measurement invariance $\left(\chi^{2}=231.12 ; d f=117\right)$. As the difference in $\chi^{2}$ was significant $\left(\Delta \chi^{2}(10)=24.01, p<.01\right)$, the hypothesis of an invariant pattern of factor loadings was rejected. The next step was to test independently the invariance of factor loading for Factors I and II. In the following model, the factor loading of Factor I was constrained equal $\left(\chi^{2}=\right.$ 215.58; $d f=111)$. As the difference in $\chi^{2}$ was nonsignificant $\left(\chi^{2}(4)=8.47, p>.05\right)$ the hypothesis of an invariant pattern of factor loadings was tenable. Lastly, testing the factor loading of Factor II was constrained equal. This model $\left(\chi^{2}\right.$ $=222.62 ; d f=113)$, is different from the congeneric model $\left(\chi^{2}(6)=15.51, p<.05\right)$, which indicates that the pattern of factor loadings is not invariant. The result of the multigroup analysis to test whether the groups have equal mean levels showed that the adult subgroup was lower than the university subgroup in Factor I as measured by this scale $(M=0.46, S E=0.09, t$-value $=5.38)$. Factor I is made up of Items 1 ("prefer to get up"), 2 ("prefer to go to bed"), 5 ("prefer to get up if you have a day off and nothing to do"),
7 ("prefer to meet with friends or attend social activities on day off"), and 8 ("prefer to eat breakfast"), and Item 9 ("prefer to eat your evening meal"). We call this factor Timetables. Factor II is made up of Items 3 ("prefer to take an important 3-hour examination"), 4 ("prefer to get up if you had a full day's work"), 6 ("prefer to do some difficult mental work which needed full concentration), 10 ("prefer to start work every day"), 11 ("prefer to do hard physical work or exercise"), and 12 ("prefer to have an important interview at which you needed to be at your best"). We call this factor Effort, as all the elements refer to the person's preference for carrying out activities requiring an effort.

\section{Discussion}

According to the analyses presented in this study, the complete CS and PS reveal adequate reliability both in the university and the adult group. These results corroborate those found in previous studies (Díaz Morales \& Sánchez-López, in press; Smith et al., 2002). Albeit this study does not provide data on the validity of the CS and PS, nonetheless both scales can be used as one-dimensional instruments, as previous studies have clearly revealed their usefulness (Bohle et al., 2001; Guthrie et al., 1995; Smith et al., 2002). Regarding the low item-scale correlation of Item 6 (exercise in the morning), preference for physical exercise in adults may be rather more affected by social factors than by a dispositional factor with a biological basis such as morningness.

In the PS, with regard to the problems found by Bohle et al. (2001), Zickar et al.(2002), and Smith et al. (2002) in Items 7 and 9, the findings of our study confirm the low itemscale correlation of Item 7 ("prefer to meet with friends or attend social activities on day off") both in the university and adult groups. Zickar et al. (2002) indicates that Item 7 has a low discrimination level. However, Item 9 ("eat your evening meal") shows an item-scale correlation which is acceptable in both groups. This item was also adequate in the sample of university students from Colombia and India used by Smith et al. (2002), which indicates the possibility of its being due to cultural differences in the evaluation of mealtimes in Colombia and India, compared to the USA, England, the Netherlands, and Spain. Our data indicate that in university students and adults, Item 9 is adequate, but this was not the case in the Spanish subsample used by Smith et al., (2002). Future studies with other samples will clarify this point. In the university group, Item 11 ("prefer to do hard physical work or exercise") shows a very low correlation, which does not appear in the adult group. Hence, our previous hypothesis about the possible importance of social versus biological factors would not be very suitable in a group of persons who may organize their activities with greater freedom of choice. Item 11, in university students, may be of little importance, as, although they are considered to be free to choose the time of day to perform various activities, most of them attend 
classes for a large part of the day and it may be in the evening when they can find time to do exercise.

This study reported evidence of age-group level consistency in factor form and loadings for the two CS factors, General Morningness and Alernness. Smith et al. (1991) found this same result only for the Alertness factor when comparing American and Japanese university students. The Alertness factor consistently appears in different samples and the data from this study indicate that, along with the General Morningness factor, it is invariant both in university students and adults. It might be considered a measurement of how easily a person becomes wide awake or how long the individual needs to achieve a minimum alertness level. Natale and Cicogna (1996) concluded that the change from sleep to waking, compared to the level of alertness, could be more representative than the change from waking to sleep to determine the circadian typology.

Regarding PS, only Factor I (Timetables) is invariant both in university students and adult samples. There has been much debate on whether sociability, as a component of extraversion, may explain relationships with morningness (Larsen, 1985). Matthews (1988) draws researchers' attention to the need for considering social aspects in addition to biological variables, as one of the main external synchronizers influencing psychological rhythms are community-based norms and timetables. Sensitivity to social synchronizers, not just to biological ones, may play an important role in adjusting the rhythm of activity to the wake/sleep rhythm across age. Although data have not been presented on the convergent validity of the scale with other objective evaluation procedures (e.g., body temperature), we consider that validation studies performed in other countries have shown that the CS is a valid scale (e.g., school timetables, Guthrie et al., 1995). Future studies may continue to explore more deeply the predictive validity of both scales.

A limitation of this work is the great heterogeneity of the adult sample. The use of other non-university samples would greatly enhance the study of the morningness. However, in this work, some relevant variables were not controlled: working time, eating habits, or wake/sleep rhythm, which may play an important role as synchronizers of circadian rhythm in adults. These data could be obtained by means of a short survey, thus allowing for the control of a greater number of relevant variables in the evaluation of circadian typology.

\section{References}

Adan, A., \& Almirall, H. (1991). Horne and Östberg MorningnessEveningness Questionnaire: A reduced scale. Personality and Individual Differences, 12, 241-253.

Alzani, V., \& Natale, A. (1998). Uno strumento per la valutazione delle differeze ne ritmi circadiani: una versione italiana della Composite Scale of Morningness. Testing Psicometría Metodología, 5, 19-31.
Bentler, P. M. (1992). On the fit of models to covariance and methodology to the Bulletin. Psychological Bulletin, 112, 400404.

Bohle, P. (1989). The impact of night work on psychological wellbeing. Ergonomics, 32, 1089-1099.

Bohle, P., Tilley, A.J., \& Brown, S. (2001). Psychometric evaluation of the Early/Late Preferences Scale. Ergonomics, 44, 887-900.

Brown, F.M. (1993). Psychometric equivalence of an improved Basic Language Morningness (BALM) Scale using industrial population within comparisons. Ergonomics, 36(13), 191-197.

Byrne, B., Shavelson, R., \& Muthén, B. (1989). Testing for the equivalence factor covariance and mean structures: The issue of partial measurement invariance. Psychological Bulletin, 105, 456-466

Caci, H., Nadalet, L., Staccini, P., Myquel, M., \& Boyer, P. (1999). Psychometric properties of the French version of the Composite Scale of Morningness in adults. European Psychiatry, 14, 284290.

Carrier, J., \& Monk, T. (2000). Circadian rhythms of performance: New trends. Chronobiology International, 17, 719-732.

Díaz Ramiro, E. (2000). Estudio de los aspectos psicológicos determinantes de la adaptación al trabajo nocturno. Unpublished doctoral dissertation. Complutense University of Madrid.

Díaz Morales, J.F., \& Sánchez-López, M.P. (in press). Propiedades psicométricas de la Escala Compuesta de Matutinidad y la Escala de Preferencias. Psicothema.

Folkard, S., \& Monk, T.H. (Eds). (1985). Hours of work: Temporal factors in work scheduling. New York: Wiley

Folkard, S., Monk, T.H., \& Lobban, M.C. (1979). Toward a predictive test of adjustment to shiftwork. Ergonomics, 22, 7991.

Furham, A., \& Hughes, K. (1999). Individual difference of nightwork and shift-work rotation. Personality and Individual Differences, 26, 941-959

Greenwood, K.N. (1994). Long-term stability and psychometric properties of the Composite Scale of Morningness. Ergonomics, 37, 377-383.

Guthrie, J.P., Ash, R.A., \& Bendapudi, V. (1995). Additional validity evidence for a measure of morningness. Journal of Applied Psychology, 80, 186-190.

Härmä, M. (1993). Individual differences in tolerance to shiftwork: A review. Ergonomics, 36, 101-109.

Horne, J.A., \& Östberg, O. (1976). A self-assessment questionnaire to determine morningness-eveningness in human circadian rhythms. International Journal of Chronobiology, 4, 97-110.

Ishihara, K., Saitoh, T., Inoue, Y., \& Miyata, K. (1984). Validity of the Japanese version of the Morningness-Eveningness Questionnaire. Perceptual and Motor Skill, 59, 863-866.

Jöreskog, K.G. (1971). Simultaneous factor analysis in several populations. Psychometrika, 36, 409-426.

Jöreskog, K.G., \& Sörbom, D. (1993). LISREL 8: Structural equation modeling with the SIMPLIS command language. Hillsdale, NJ: Scientific Software International. 
Kerkhof, G. (1985). Inter-individual differences in the human circadian system: A review. Biological Psychology, 20, 83-112.

Koscec, A., Radosevic-Vidacek, B., \& Kostovic, M. (2001). Morningness-eveningness across two student generations: Would two decades make a difference? Personality and Individual Differences, 31, 627-638.

Luijben, T. (1989). Statistical guidance for model modification in covariance structure analysis. Amsterdam: Sociometric Research Foundation.

Matthews, G. (1988). Morningness-eveningness as a dimension of personality: Trait, state and psychopshysiological correlates. European Journal of Personality, 2, 277-293.

Mecacci, L., \& Rochetti, G. (1998). Morning and evening types: Stress-related personality aspects. Personality and Individual Differences, 25, 537-542.

Moog, R. (1981). Morning-evening types and shiftwork. A questionnaire study. In A. Reinberg, N. Vieux \& P. Andlauer (Eds.). Night and shiftwork: Biological and social aspects (pp. 481-488). Oxford: Pergamon Press.

Natale, A. \& Alzani, V. (2001). Additional validity evidence for the Composite Scale of Morningness. Personality and Individual Differences, 30, 293-301.

Natale, V., \& Cicogna, P. (1996). Circadian regulation of subjective alertness in morning and evening "types." Personality and Individual Differences, 20, 491-296.

Pornpitakpan, C. (1998). Psychometric properties of the Composite Scale of Morningness: A shortened version. Personality and Individual Differences, 25, 699-709.

Pornpitakpan, C. (2000). Additional validity of the Basic Language Morningness (BALM) Scale. Personality and Individual Differences, 28, 59-72.

Roberts, R., \& Kyllonen, P. (1999). Morningness-eveningness and intelligence: Early to bed, early to rise will likely make you anything but wise! Personality and Individual Differences, 27, 1123-1133.

Roberts, R. D., \& Irvine, S. (1999). Development and construct validation of the Lark-Owl (Chronotype) Indicator (LOCI): Technical Report. Manuscript in Preparation.
Smith, C., Folkard, S., Schmieder, R., Parra, L., Spelten, E., Almirall, H., Sen, R., Sahu, S., Pérez, L., \& Tisak, J. (2002). Investigation of morning-evening orientations in six countries using the Preferences Scale. Personality an Individual Differences, 32, 949-968.

Smith, C., Folkard, S., Schmieder, R., Parra, L., Spelten, E., \& Almirall, H. (October, 1993). The Preferences Scale: Multinational assessment of a new measure of morningness. Poster presented at the $37^{\text {th }}$ Annual Meeting of the Human Factors and Ergonomics Society, Seattle, WA.

Smith, C., Reilly, C., \& Midkiff, K. (1989). Evaluation of three circadian rhythm questionnaires with suggestions for an improved measure of morningness. Journal of Applied Psychology, 74, 728-738.

Smith, C., Tisak, J., Bauman, T., \& Green, E. (1991). Psychometric equivalence of a translated circadian rhythm questionnaire: Implications for between- and within-population assessment. Journal of Applied Psychology, 76, 628-636.

Smith, R.S., Guilleminault, C., \& Efron, B. (1997). Circadian rhythms and enhanced athletic performance in the national football league. Sleep, 20, 362-365.

SPSS, Inc. (1988). SPSS-X user's guide. New York: McGraw Hill Tankova, I., Adan, A., \& Buela-Casal, G. (1994). Circadian typology and individual differences. A review. Personality an Individual Differences, 16, 671-684.

Testu, F. (1989). Chronopsychologie et rythmes scolaires. París: Masson.

Torsvall, L., \& Åkerstdt, T. (1980). A diurnal type scale. Scandinavian Journal of Work and Environmental Health, 6, 283-290.

Webb, W. (1982). Biological rhythms, sleep, and performance. New York: Wiley.

Zickar, M., Russell, S., Smith, C., Bohle, P., \& Tilley, A. (2002). Evaluating two morningness scales with item response theory. Personality and Individual Differences, 33, 11-24.

Received June, 14, 2004 Revision received September, 2, 2004 Accepted September, 15, 2004 